\title{
Some Common Fixed Point Theorems for F-Contraction Type Mappings in 0-Complete Partial Metric Spaces
}

\author{
Satish Shukla ${ }^{1}$ and Stojan Radenovic ${ }^{2}$ \\ ${ }^{1}$ Department of Applied Mathematics, Shri Vaishnav Institute of Technology \& Science, Gram Baroli Sanwer Road, Indore, \\ Madhya Pradesh 453331, India \\ ${ }^{2}$ Faculty of Mechanical Engineering, University of Belgrade, Kraljice Marije 16, 11120 Belgrad, Serbia
}

Correspondence should be addressed to Stojan Radenović; sradenovic@mas.bg.ac.rs

Received 11 January 2013; Accepted 22 February 2013

Academic Editor: Bibhas R. Majhi

Copyright ( $\odot 2013$ S. Shukla and S. Radenović. This is an open access article distributed under the Creative Commons Attribution License, which permits unrestricted use, distribution, and reproduction in any medium, provided the original work is properly cited.

We prove some common fixed point theorems for $F$-contractions in 0-complete partial metric spaces. Our results extend, generalize, and unify several known results in the literature. Some examples are included which show that the generalization is proper.

\section{Introduction and Preliminaries}

In 1994, Matthews [1] introduced the notion of partial metric spaces, as a part of the study of denotational semantics of dataflow network. In partial metric space, the usual distance was replaced by partial metric, with an interesting property "nonzero self-distance" of points. Also, the convergence of sequences in this space was defined in such a way that the limit of a convergent sequence need not be unique. Matthews showed that the Banach contraction principle is valid in partial metric space and can be applied in program verification. Later, several authors generalized the result of Matthews (see, e.g., [2-29]). O’Neill [22] generalized the concept of partial metric space a bit further by admitting negative distances. The partial metric defined by O'Neill is called dualistic partial metric. Heckmann [21] generalized it by omitting small selfdistance axiom. The partial metric defined by Heckmann is called weak partial metric.

Romaguera [23] introduced the notion of 0-Cauchy sequence, 0 -complete partial metric spaces and proved some characterizations of partial metric spaces in terms of completeness and 0 -completeness. The notion of 0 -complete partial metric spaces is more general than the complete partial metric space, as shown by an example in [23].

Recently, Wardowski [30] introduces a new concept of $F$-contraction and proves a fixed point theorem which generalizes the Banach contraction principle in a different way than the known results of the literature on complete metric spaces. In this paper, we consider a more generalized type of $F$-contraction and prove some common fixed point theorems for such type of mappings in 0-complete partial metric spaces. The results of this paper generalize and extend the results of Wardowski [30], Altun et al. [17], Ćirić [31, 32], and some well-known results in the literature. Some examples are given which show that the results of this paper are proper generalizations of known results.

First we recall some definitions and properties of partial metric space $[1,22,23,25,33]$.

Definition 1. A partial metric on a nonempty set $X$ is a function $p: X \times X \rightarrow \mathbb{R}^{+}$( $\mathbb{R}^{+}$stands for nonnegative reals) such that for all $x, y$, and $z \in X$

(P1) $x=y$ if and only if $p(x, x)=p(x, y)=p(y, y)$;

(P2) $p(x, x) \leq p(x, y)$;

(P3) $p(x, y)=p(y, x)$;

(P4) $p(x, y) \leq p(x, z)+p(z, y)-p(z, z)$.

A partial metric space is a pair $(X, p)$ such that $X$ is a nonempty set, and $p$ is a partial metric on $X$.

It is clear that, if $p(x, y)=0$, then from (P1) and (P2) $x=y$. But if $x=y, p(x, y)$ may not be 0 . Also every metric space is a partial metric space, with zero self-distance. 
Each partial metric on $X$ generates a $T_{0}$ topology $\tau_{p}$ on $X$ which has a base of the family of open $p$-balls $\left\{B_{p}(x, \varepsilon): x \in\right.$ $X, \varepsilon>0\}$, where $B_{p}(x, \varepsilon)=\{y \in X: p(x, y)<p(x, x)+\varepsilon\}$ for all $x \in X$ and $\varepsilon>0$.

Definition 2. A mapping $f: X \rightarrow X$ is continuous if and only if, whenever a sequence $\left\{x_{n}\right\}$ in $X$ converges with respect to $\tau_{p}$ to a point $x \in X$, the sequence $\left\{f x_{n}\right\}$ converges with respect to $\tau_{p}$ to $f x \in X$.

Theorem 3 (see [1]). For each partial metric $p: X \times X \rightarrow \mathbb{R}^{+}$ the pair $(X, d)$, where $d(x, y)=2 p(x, y)-p(x, x)-p(y, y)$ for all $x, y \in X$, is a metric space.

Here $(X, d)$ is called induced metric space, and $d$ is induced metric. In further discussion until specified, $(X, d)$ will represent induced metric space.

Example 4 (see [1]). If $p: \mathbb{R}^{+} \times \mathbb{R}^{+} \rightarrow \mathbb{R}^{+}$is defined by $p(x, y)=\max \{x, y\}$, for all $x, y \in \mathbb{R}^{+}$, then $\left(\mathbb{R}^{+}, p\right)$ is a partial metric space.

Example 5. Let $(X, p)$ be a partial metric space; then $\left(X, p^{*}\right)$ is a partial metric space, where $p^{*}(x, y)=d(x, y)+p(x, y)$ for all $x, y \in X$ and $d$ is the metric induced by $p$.

For some more examples of partial metric spaces, we refer to [14] and the references therein.

Let $(X, p)$ be a partial metric space.

(1) A sequence $\left\{x_{n}\right\}$ in $(X, p)$ converges to a point $x \in X$ if and only if $p(x, x)=\lim _{n \rightarrow \infty} p\left(x_{n}, x\right)$.

(2) A sequence $\left\{x_{n}\right\}$ in $(X, p)$ is called the Cauchy sequence if there exists (and is finite) $\lim _{n, m \rightarrow \infty} p\left(x_{n}\right.$, $\left.x_{m}\right)$.

(3) $(X, p)$ is said to be complete if every Cauchy sequence $\left\{x_{n}\right\}$ in $X$ converges with respect to $\tau_{p}$ to a point $x \in X$ such that $p(x, x)=\lim _{n, m \rightarrow \infty} p\left(x_{n}, x_{m}\right)$.

(4) A sequence $\left\{x_{n}\right\}$ in $(X, p)$ is called 0 -Cauchy sequence if $\lim _{n, m \rightarrow \infty} p\left(x_{n}, x_{m}\right)=0$. The space $(X, p)$ is said to be 0 -complete if every 0 -Cauchy sequence in $X$ converges with respect to $\tau_{p}$ to a point $x \in X$ such that $p(x, x)=0$.

Lemma 6 (see $[1,23,25,33])$. Let $(X, p)$ be a partial metric space and $\left\{x_{n}\right\}$ any sequence in $X$.

(i) $\left\{x_{n}\right\}$ is a Cauchy sequence in $(X, p)$ if and only if it is a Cauchy sequence in metric space $(X, d)$.

(ii) $(X, p)$ is complete if and only if the metric space $(X, d)$ is complete. Furthermore, $\lim _{n \rightarrow \infty} d\left(x_{n}, x\right)=0$ if and only if $p(x, x)=\lim _{n \rightarrow \infty} p\left(x_{n}, x\right)=\lim _{n, m \rightarrow \infty} p\left(x_{n}\right.$, $\left.x_{m}\right)$.

(iii) Every 0-Cauchy sequence in $(X, p)$ is Cauchy in $(X, d)$.

(iv) If $(X, p)$ is complete, then it is 0 -complete.

The converse assertions of (iii) and (iv) do not hold. Indeed, the partial metric space $\left(\mathbb{Q} \cap \mathbb{R}^{+}, p\right)$, where $\mathbb{Q}$ denotes the set of rational numbers and the partial metric $p$ is given by $p(x, y)=\max \{x, y\}$, provides an easy example of a 0 -complete partial metric space which is not complete. Also, it is easy to see that every closed subset of a 0 -complete partial metric space is 0 -complete.

The proof of the following lemma is easy, and for detail we refer to [34] and the references therein.

Lemma 7. Assume $x_{n} \rightarrow z$ as $n \rightarrow \infty$ in a partial metric space $(X, p)$ such that $p(z, z)=0$. Then $\lim _{n \rightarrow \infty} p\left(x_{n}, y\right)=p(z, y)$ for all $y \in X$.

Analogous to [30] we have following definitions.

Definition 8. Let $F: \mathbb{R}^{+} \rightarrow \mathbb{R}$ be a mapping satisfying:

(F1) $F$ is strictly increasing, that is, for $\alpha, \beta \in \mathbb{R}^{+}$such that $\alpha<\beta$ implies $F(\alpha)<F(\beta)$;

(F2) for each sequence $\left\{\alpha_{n}\right\}$ of positive numbers $\lim _{n \rightarrow \infty} \alpha_{n}=0$ if and only if $\lim _{n \rightarrow \infty} F\left(\alpha_{n}\right)=-\infty$;

(F3) there exists $k \in(0,1)$ such that $\lim _{\alpha \rightarrow 0^{+}} \alpha^{k} F(\alpha)=0$.

For examples of function $F$, we refer to [30]. We denote the set of all functions satisfying properties $(\mathrm{F} 1)-(\mathrm{F} 3)$ by $\mathscr{F}$.

Wardowski in [30] defined the F-contraction as follows.

Let $(X, \rho)$ be a metric space. A mapping $T: X \rightarrow X$ is said to be an $F$-contraction if there exists $F \in \mathscr{F}$ and $\tau>0$ such that, for all $x, y \in X, \rho(T x, T y)>0$, we have

$$
\tau+F(\rho(T x, T y)) \leq F(\rho(x, y)) .
$$

The following lemma will be useful in proving our main result.

Lemma 9. Let $(X, p)$ be a partial metric space and $f, g: X \rightarrow$ $X$ two mappings. Suppose there exist $F \in \mathscr{F}$ and $\tau>0$ such that, for all $x, y \in X, p(f x, g y)>0$, one has

$$
\begin{aligned}
& \tau+F(p(f x, g y)) \\
& \leq F(\max \{p(x, y), p(x, f x), p(y, g y), \\
&\left.\left.\frac{p(x, g y)+p(y, f x)}{2}\right\}\right) .
\end{aligned}
$$

If $f$ has a fixed point $u \in X$, then $u$ is a unique common fixed point of $f$ and $g$, and $p(u, u)=0$.

Proof. Let $u \in X$ be a fixed point of $f$. Suppose $p(f u, g u)>0$; then by (2) we obtain

$$
\begin{aligned}
\tau+F(p(f u, g u)) \leq F(\max \{p(u, u), p(u, f u), p(u, g u), & \left.\left.\frac{p(u, g u)+p(u, f u)}{2}\right\}\right),
\end{aligned}
$$




$$
\begin{gathered}
\tau+F(p(u, g u)) \\
\leq F\left(\max \left\{p(u, g u), \frac{p(u, u)+p(u, g u)}{2}\right\}\right), \\
\tau+F(p(u, g u)) \leq F(p(u, g u)),
\end{gathered}
$$

a contradiction (as $\tau>0)$. Therefore we have $p(f u, g u)=0$; that is, $f u=g u=u$. Thus $u$ is a common fixed point of $f$ and $g$. Again, if $p(u, u)>0$, then by a similar process as above we obtain

$$
\begin{aligned}
\tau+F(p(u, u)) & =\tau+F(p(f u, g u)) \leq F(p(u, g u)) \\
& =F(p(u, u))
\end{aligned}
$$

a contradiction (as $\tau>0$ ). Therefore, $p(u, u)=0$. For uniqueness, let $v$ be another common fixed point of $f$ and $g$; that is, $f v=g v=v$. If $p(u, v)>0$, then by (2) we obtain

$$
\begin{aligned}
\tau+ & F(p(u, v)) \\
= & \tau+F(p(f u, g v)) \\
\leq & F(\max \{p(u, v), p(u, f u), p(v, g v), \\
& \left.\left.\frac{p(u, g v)+p(v, f u)}{2}\right\}\right) \\
= & F\left(\max \left\{p(u, v), p(u, u), p(v, v), \frac{p(u, v)+p(v, u)}{2}\right\}\right) \\
= & F(p(u, v)),
\end{aligned}
$$

a contradiction. Therefore, $p(u, v)=0$; that is, $u=v$. Thus a common fixed point is unique.

Now we can state our main results.

\section{Main Results}

The following theorem extends and generalizes the results of [30] in partial metric spaces.

Theorem 10. Let $(X, p)$ be a 0 -complete partial metric space and $f, g: X \rightarrow X$ two mappings. Suppose there exist $F \in \mathscr{F}$ and $\tau>0$ such that, for all $x, y \in X, p(f x, g y)>0$, one has

$$
\begin{aligned}
& \tau+F(p(f x, g y)) \\
& \leq F(\max \{p(x, y), p(x, f x), p(y, g y), \\
&\left.\left.\frac{p(x, g y)+p(y, f x)}{2}\right\}\right) .
\end{aligned}
$$

If ( $i) f$ or $g$ is continuous or (ii) $F$ is continuous, then $f$ and $g$ have a unique common fixed point $u \in X$, and $p(u, u)=0$.
Proof. Let $x_{0} \in X$ be arbitrary. Define a sequence $\left\{x_{n}\right\}$ by $x_{2 n+1}=f x_{2 n}$, and $x_{2 n+2}=g x_{2 n+1}$ for all $n \geq 0$. If $x_{m+1}=x_{m}$ for any $m \in \mathbb{N}$, for example, let $x_{2 n+1}=x_{2 n}$, then it follows from (6) that

$$
\begin{aligned}
& \tau+ F\left(p\left(x_{2 n+1}, x_{2 n+2}\right)\right) \\
&= \tau+F\left(p\left(f x_{2 n}, g x_{2 n+1}\right)\right) \\
& \leq \\
&\left.\left.\frac{p\left(x_{2 n}, g x_{2 n+1}\right)+p\left(x_{2 n+1}, f x_{2 n}\right)}{2}\right\}\right) \\
&= F\left(\operatorname { m a x } \left\{p\left(x_{2 n}, x_{2 n+1}\right), p\left(x_{2 n}, f x_{2 n}\right), p\left(x_{2 n+1}, g x_{2 n+1}\right),\right.\right. \\
&\left.\left.\frac{p\left(x_{2 n}, x_{2 n+2}\right)+p\left(x_{2 n+1}, x_{2 n+1}\right)}{2}\right\}\right) \\
&=F\left(\operatorname { m a x } \left\{p\left(x_{2 n}, x_{2 n}\right), p\left(x_{2 n}, x_{2 n}\right), p\left(x_{2 n}, x_{2 n+2}\right), p\left(x_{2 n+1}, x_{2 n+2}\right),\right.\right. \\
&\left.\left.\frac{p\left(x_{2 n}, x_{2 n+2}\right)+p\left(x_{2 n}, x_{2 n}\right)}{2}\right\}\right) \\
&=F\left(p\left(x_{2 n}, x_{2 n+2}\right)\right),
\end{aligned}
$$

that is, $F\left(p\left(x_{2 n}, x_{2 n+2}\right)\right) \leq F\left(p\left(x_{2 n}, x_{2 n+2}\right)\right)-\tau$. As, $\tau>0$, we get a contradiction. Therefore, we must have $F\left(p\left(x_{2 n}\right.\right.$, $\left.\left.x_{2 n+2}\right)\right)=0$; that is, $x_{2 n}=x_{2 n+1}=x_{2 n+2}$. Similarly, we obtain $x_{2 n}=x_{2 n+1}=x_{2 n+2}=x_{2 n+3}=\cdots$, and so $x_{2 n}=f x_{2 n}=g x_{2 n}$. Thus, $x_{2 n}$ is a common fixed point of $f$ and $g$. Now, we assume that $x_{m} \neq x_{m+1}$ for all $m \in \mathbb{N}$; then it follows from (6) that

$$
\begin{aligned}
& \tau+F\left(p\left(x_{2 n+1}, x_{2 n}\right)\right) \\
& =\tau+F\left(p\left(f x_{2 n}, g x_{2 n-1}\right)\right) \\
& \leq F\left(\operatorname { m a x } \left\{p\left(x_{2 n}, x_{2 n-1}\right), p\left(x_{2 n}, f x_{2 n}\right), p\left(x_{2 n-1}, g x_{2 n-1}\right)\right.\right. \text {, } \\
& \left.\left.\frac{p\left(x_{2 n}, g x_{2 n-1}\right)+p\left(x_{2 n-1}, f x_{2 n}\right)}{2}\right\}\right) \\
& =F\left(\operatorname { m a x } \left\{p\left(x_{2 n}, x_{2 n-1}\right), p\left(x_{2 n}, x_{2 n+1}\right), p\left(x_{2 n-1}, x_{2 n}\right)\right.\right. \text {, } \\
& \left.\left.\frac{p\left(x_{2 n}, x_{2 n}\right)+p\left(x_{2 n-1}, x_{2 n+1}\right)}{2}\right\}\right) \\
& \leq F\left(\operatorname { m a x } \left\{p\left(x_{2 n}, x_{2 n-1}\right), p\left(x_{2 n}, x_{2 n+1}\right),\right.\right. \\
& \left.\left.\frac{p\left(x_{2 n-1}, x_{2 n}\right)+p\left(x_{2 n}, x_{2 n+1}\right)}{2}\right\}\right) \\
& =F\left(\max \left\{p\left(x_{2 n}, x_{2 n-1}\right), p\left(x_{2 n}, x_{2 n+1}\right)\right\}\right) \text {. }
\end{aligned}
$$


If $\max \left\{p\left(x_{2 n}, x_{2 n-1}\right), p\left(x_{2 n}, x_{2 n+1}\right)\right\}=p\left(x_{2 n}, x_{2 n+1}\right)$, then it follows from the above inequality that $\tau+F\left(p\left(x_{2 n+1}, x_{2 n}\right)\right) \leq$ $F\left(p\left(x_{2 n}, x_{2 n+1}\right)\right)$, a contradiction (as $\left.\tau>0\right)$. Therefore, we must have $\max \left\{p\left(x_{2 n}, x_{2 n-1}\right), p\left(x_{2 n}, x_{2 n+1}\right)\right\}=p\left(x_{2 n}, x_{2 n-1}\right)$. So, setting $p_{n}=p\left(x_{n}, x_{n+1}\right)$ from the above inequality we obtain that

$$
F\left(p_{2 n}\right) \leq F\left(p_{2 n-1}\right)-\tau \text {. }
$$

Again, using (6) we obtain

$$
\begin{aligned}
& \tau+F\left(p\left(x_{2 n+2}, x_{2 n+1}\right)\right) \\
& =\tau+F\left(p\left(g x_{2 n+1}, f x_{2 n}\right)\right)=\tau+F\left(p\left(f x_{2 n}, g x_{2 n+1}\right)\right) \\
& \leq F\left(\operatorname { m a x } \left\{p\left(x_{2 n}, x_{2 n+1}\right), p\left(x_{2 n}, f x_{2 n}\right), p\left(x_{2 n+1}, g x_{2 n+1}\right)\right.\right. \text {, } \\
& \left.\left.\frac{p\left(x_{2 n}, g x_{2 n+1}\right)+p\left(x_{2 n+1}, f x_{2 n}\right)}{2}\right\}\right) \\
& =F\left(\operatorname { m a x } \left\{p\left(x_{2 n}, x_{2 n+1}\right), p\left(x_{2 n}, x_{2 n+1}\right), p\left(x_{2 n+1}, x_{2 n+2}\right)\right.\right. \text {, } \\
& \left.\left.\frac{p\left(x_{2 n}, x_{2 n+2}\right)+p\left(x_{2 n+1}, x_{2 n+1}\right)}{2}\right\}\right) \\
& \leq F\left(\operatorname { m a x } \left\{p\left(x_{2 n}, x_{2 n+1}\right), p\left(x_{2 n+1}, x_{2 n+2}\right)\right.\right. \text {, } \\
& \left.\left.\frac{p\left(x_{2 n}, x_{2 n+1}\right)+p\left(x_{2 n+1}, x_{2 n+2}\right)}{2}\right\}\right) \\
& =F\left(\max \left\{p\left(x_{2 n}, x_{2 n+1}\right), p\left(x_{2 n+1}, x_{2 n+2}\right)\right\}\right) \text {. }
\end{aligned}
$$

If $\max \left\{p\left(x_{2 n}, x_{2 n+1}\right), p\left(x_{2 n+1}, x_{2 n+2}\right)\right\}=p\left(x_{2 n+1}, x_{2 n+2}\right)$, then it follows from the above inequality that $\tau+F\left(p\left(x_{2 n+2}\right.\right.$, $\left.\left.x_{2 n+1}\right)\right) \leq F\left(p\left(x_{2 n+2}, x_{2 n+1}\right)\right)$, a contradiction (as $\left.\tau>0\right)$. Therefore, we must have $\max \left\{p\left(x_{2 n}, x_{2 n+1}\right), p\left(x_{2 n+1}, x_{2 n+2}\right)\right\}=$ $p\left(x_{2 n}, x_{2 n+1}\right)$. So from the above inequality we obtain that

$$
F\left(p_{2 n+1}\right) \leq F\left(p_{2 n}\right)-\tau \text {. }
$$

Using (9) and (11) we obtain

$$
\begin{aligned}
F\left(p_{2 n}\right) & \leq F\left(p_{2 n-1}\right)-\tau \\
& \leq F\left(p_{2 n-2}\right)-2 \tau \leq \cdots \leq F\left(p_{0}\right)-2 n \tau
\end{aligned}
$$

Similarly

$$
\begin{aligned}
F\left(p_{2 n+1}\right) & \leq F\left(p_{2 n}\right)-\tau \\
& \leq F\left(p_{2 n-1}\right)-2 \tau \leq \cdots \leq F\left(p_{0}\right)-(2 n+1) \tau .
\end{aligned}
$$

It follows from (12) and (13) that $\lim _{n \rightarrow \infty} F\left(p_{n}\right)=-\infty$. As $F \in \mathscr{F}$ by $(\mathrm{F} 2)$ we have

$$
\lim _{n \rightarrow \infty} p_{n}=0
$$

Again, by (F3), there exists $k \in(0,1)$ such that

$$
\lim _{n \rightarrow \infty} p_{n}^{k} F\left(p_{n}\right)=0
$$

From (12) and (13) we have

$$
\begin{gathered}
p_{2 n}^{k}\left[F\left(p_{2 n}\right)-F\left(p_{0}\right)\right] \leq-2 n p_{2 n}^{k} \tau \leq 0, \\
p_{2 n+1}^{k}\left[F\left(p_{2 n+1}\right)-F\left(p_{0}\right)\right] \leq-(2 n+1) p_{2 n+1}^{k} \tau \leq 0 .
\end{gathered}
$$

Using (14) and (15) in the above inequalities we obtain

$$
\lim _{n \rightarrow \infty} n\left(p_{n}\right)^{k}=0
$$

It follows from above that there exists $n_{0} \in \mathbb{N}$ such that $n\left(p_{n}\right)^{k}<1$ for all $n>n_{0}$; that is,

$$
p_{n}<\frac{1}{n^{1 / k}}, \quad \forall n>n_{0}
$$

Let $m, n \in \mathbb{N}$ with $m>n>n_{0}$; then it follows from (18) that

$$
\begin{aligned}
p\left(x_{n}, x_{m}\right) \leq & p\left(x_{n}, x_{n+1}\right)+p\left(x_{n+1}, x_{n+2}\right)+\cdots+p\left(x_{m-1}, x_{m}\right) \\
& -\left[p\left(x_{n+1}, x_{n+1}\right)+p\left(x_{n+2}, x_{n+2}\right)\right. \\
& \left.\quad+\cdots+p\left(x_{m-1}, x_{m-1}\right)\right] \\
\leq & p_{n}+p_{n+1}+\cdots \\
\leq & \frac{1}{n^{1 / k}}+\frac{1}{(n+1)^{1 / k}}+\cdots \\
= & \sum_{i=n}^{\infty} \frac{1}{i^{1 / k}}
\end{aligned}
$$

As $k \in(0,1)$, therefore the series $\sum_{i=n}^{\infty} 1 / i^{1 / k}$ converges; so it follows from the above inequality that $\lim _{n \rightarrow \infty} p\left(x_{n}, x_{m}\right)=$ 0 ; that is, the sequence $\left\{x_{n}\right\}$ is a 0 -Cauchy sequence in $X$. Therefore, by 0 -completeness of $(X, p)$, there exists $u \in X$ such that

$$
\lim _{n, m \rightarrow \infty} p\left(x_{n}, x_{m}\right)=\lim _{n \rightarrow \infty} p\left(x_{n}, u\right)=p(u, u)=0 .
$$

We will prove that $u$ is a common fixed point of $f$ and $g$. We consider two cases.

Case 1. Suppose $f$ is continuous. Using continuity of $f,(20)$, and Lemma 7 we obtain

$$
\begin{aligned}
p(u, f u) & =\lim _{n \rightarrow \infty} p\left(x_{2 n+1}, f u\right) \\
& =\lim _{n \rightarrow \infty} p\left(f x_{2 n}, f u\right)=p(f u, f u) .
\end{aligned}
$$

We claim that $p(f u, f u)=0$. Suppose $p(f u, f u)>0$. If for each $n \in \mathbb{N}$ there exists $k_{n}$ such that $p\left(x_{k_{n}+1}, f u\right)=0$ and $k_{n}>k_{n-1}$ with $k_{0}=1$, then by Lemma 7 and (20) we have $f u=u$, and so, by Lemma $9, u$ is a unique common fixed point of $f$ and $g$. 
Now suppose there exists $n_{1} \in \mathbb{N}$ such that $p\left(f u, g x_{n}\right)>0$ for all $n \geq n_{1}$. Then, since $p(f u, f u)>0$, there exists $\varepsilon>0$ such that $p(f u, f u)>\varepsilon$.

For any $n \geq n_{1}$ we have

$$
\begin{gathered}
\tau+F\left(p\left(f u, g x_{2 n+1}\right)\right) \\
\leq F\left(\operatorname { m a x } \left\{p\left(u, x_{2 n+1}\right), p(u, f u), p\left(x_{2 n+1}, g x_{2 n+1}\right),\right.\right. \\
\left.\left.\frac{p\left(u, g x_{2 n+1}\right)+p\left(x_{2 n+1}, f u\right)}{2}\right\}\right) \\
=F\left(\operatorname { m a x } \left\{p\left(u, x_{2 n+1}\right), p(f u, f u), p\left(x_{2 n+1}, x_{2 n+2}\right),\right.\right. \\
\left.\left.\frac{p\left(u, x_{2 n+2}\right)+p\left(x_{2 n+1}, f u\right)}{2}\right\}\right) .
\end{gathered}
$$

Using (20) and (21), there exists $n_{2} \in \mathbb{N}$ such that $p(u$, $\left.x_{2 n+1}\right), p\left(x_{2 n+1}, x_{2 n+2}\right)<\varepsilon / 2$ and $p\left(x_{2 n+1}, f u\right)<p(f u, f u)+$ $\varepsilon / 2$ for all $n>n_{2}$; therefore, it follows from the above inequality that

$$
\begin{aligned}
\tau+ & F\left(p\left(f u, g x_{2 n+1}\right)\right) \\
\leq & F\left(\operatorname { m a x } \left\{\frac{\varepsilon}{2}, p(f u, f u), \frac{\varepsilon}{2},\right.\right. \\
& \left.\left.\frac{\varepsilon / 2+p(f u, f u)+\varepsilon / 2}{2}\right\}\right), \\
& F\left(p\left(f u, g x_{2 n+1}\right)\right)<F(p(f u, f u)) .
\end{aligned}
$$

As $F \in \mathscr{F}$, by $(F 1)$ we have $p\left(f u, g x_{2 n+1}\right)<p(f u, f u)$ for all $n>\max \left\{n_{1}, n_{2}\right\}$, a contradiction. Therefore, we must have $p(f u, f u)=p(u, f u)=0$; that is, $f u=u$, and by Lemma 9, $u$ is a unique common fixed point of $f$ and $g$. Similarly, if $g$ is continuous, then $u$ is a unique common fixed point of $f$ and $g$.

Case 2. Now suppose that $F$ is continuous. We can assume that there exists $n_{3}$ such that $p\left(x_{n}, f u\right)>0$ for all $n \geq n_{3}$; otherwise we get $f u=u$ (similar as in previous case).

For any $n \geq n_{3}$, we obtain from (6) that

$$
\begin{aligned}
\tau+ & F\left(p\left(f u, x_{2 n+2}\right)\right) \\
& =\tau+F\left(p\left(f u, g x_{2 n+1}\right)\right) \\
\leq & F\left(\operatorname { m a x } \left\{p\left(u, x_{2 n+1}\right), p(u, f u), p\left(x_{2 n+1}, g x_{2 n+1}\right),\right.\right. \\
& \left.\left.\frac{p\left(u, g x_{2 n+1}\right)+p\left(x_{2 n+1}, f u\right)}{2}\right\}\right) \\
\leq & F\left(\operatorname { m a x } \left\{p\left(u, x_{2 n+1}\right), p(u, f u), p\left(x_{2 n+1}, x_{2 n+2}\right),\right.\right. \\
& \left.\left.\frac{p\left(u, x_{2 n+2}\right)+p\left(x_{2 n+1}, u\right)+p(u, f u)}{2}\right\}\right) .
\end{aligned}
$$

From (20), there exists $n_{4} \in \mathbb{N}$ such that

$$
\begin{aligned}
\max \left\{p\left(u, x_{2 n+1}\right), p(u, f u), p\left(x_{2 n+1}, x_{2 n+2}\right),\right. & \\
& \left.\frac{p\left(u, x_{2 n+2}\right)+p\left(x_{2 n+1}, u\right)+p(u, f u)}{2}\right\}=p(u, f u),
\end{aligned}
$$

for all $n>n_{4}$. Therefore, it follows from (24) that

$$
\tau+F\left(p\left(f u, x_{2 n+2}\right)\right) \leq F(p(u, f u)), \quad \forall n>\max \left\{n_{3}, n_{4}\right\} .
$$

Using continuity of $F$ and letting $n \rightarrow \infty$ in the above inequality we obtain

$$
\tau+F(p(f u, u)) \leq F(p(u, f u)),
$$

a contradiction (as $\tau>0)$. Therefore we must have $p(u, f u)=$ 0 ; that is, $f u=u$. Again by Lemma $9 u$ is a unique common fixed point of $f$ and $g$.

The following corollaries are immediate consequences of Theorem 10.

Corollary 11. Let $(X, p)$ be a 0 -complete partial metric space and $f, g: X \rightarrow X$ two mappings. Suppose there exist $F \in \mathscr{F}$ and $\tau>0$ such that, for all $x, y \in X, p(f x, g y)>0$, one has

$$
\tau+F(p(f x, g y)) \leq F(\max \{p(x, y), p(x, f x), p(y, g y)\}) .
$$

If ( $i) f$ or $g$ is continuous or (ii) $F$ is continuous, then $f$ and $g$ have a unique common fixed point $u \in X$, and $p(u, u)=0$.

Corollary 12. Let $(X, p)$ be a 0 -complete partial metric space and $f, g: X \rightarrow X$ two mappings. Suppose there exist $F \in \mathscr{F}$ and $\tau>0$ such that, for all $x, y \in X, p(f x, g y)>0$, one has

$$
\tau+F(p(f x, g y)) \leq F(p(x, y)) .
$$

If ( $i) f$ or $g$ is continuous or (ii) $F$ is continuous, then $f$ and $g$ have a unique common fixed point $u \in X$, and $p(u, u)=0$.

Taking $f=g$ in Theorem 10 we obtain the following corollary.

Corollary 13. Let $(X, p)$ be a 0 -complete partial metric space and $f: X \rightarrow X$ a mapping. Suppose there exist $F \in \mathscr{F}$ and $\tau>0$ such that, for all $x, y \in X, p(f x, f y)>0$, one has

$$
\begin{aligned}
& \tau+F(p(f x, f y)) \\
& \leq F(\max \{p(x, y), p(x, f x), p(y, f y), \\
&\left.\left.\frac{p(x, f y)+p(y, f x)}{2}\right\}\right) .
\end{aligned}
$$

If ( $i) f$ is continuous or (ii) $F$ is continuous, then $f$ has a unique fixed point $u \in X$, and $p(u, u)=0$. 
The following is a fixed point result for $F$-contraction in 0 complete partial metric space and follows from Corollary 13.

Corollary 14. Let $(X, p)$ be a 0 -complete partial metric space and $f: X \rightarrow X$ a mapping. Suppose there exist $F \in \mathscr{F}$ and $\tau>0$ such that, for all $x, y \in X, p(f x, f y)>0$, one has

$$
\tau+F(p(f x, f y)) \leq F(p(x, y)) .
$$

If ( $i) f$ is continuous or (ii) $F$ is continuous, then $f$ has a unique fixed point $u \in X$, and $p(u, u)=0$.

The following are some examples which illustrate the above results and that the generalizations are proper.

Example 15. Let $X=[0,1] \cap \mathbb{Q}$, and let $p: X \times X \rightarrow \mathbb{R}^{+}$be defined by $p(x, y)=\max \{x, y\}$ for all $x, y \in X$. Then $(X, p)$ is a 0 -complete partial metric space, but it is not complete partial metric space. Indeed, the induced metric space $(X, d)$, where $d(x, y)=|x-y|$ for all $x, y \in X$, is not a complete metric space. Define $f: X \rightarrow X$ by

$$
f x= \begin{cases}\frac{x}{4}, & \text { if } x \in[0,1) \\ \frac{1}{8}, & \text { if } x=1\end{cases}
$$

We note that $f$ satisfies the condition (31) of Corollary 14 with $F(t)=\log t$ for all $t \in \mathbb{R}^{+}, \tau \in(0, \log 4]$, and $0 \in X$ is unique fixed point of $f$ with $p(0,0)=0$. On the other hand, the metric version of Corollary 14 is not applicable because $(X, d)$ is not complete metric space. Also, this example shows that the class of $F$-contraction in partial metric spaces is wider than that in metric spaces. Indeed, for $x=1, y=9 / 10$, there is no $F \in \mathscr{F}$ and $\tau>0$ such that $\tau+F(d(f x, f y)) \leq F(d(x, y))$, where $d$ is usual as well as the metric induced by $p$.

The following example illustrates the case when Corollary 11 is applicable, while Corollary 12 is not, as well as the metric versions of Corollary 11 are not applicable.

Example 16. Let $X=\{0,1,2,3\}$, and let $p: X \times X \rightarrow \mathbb{R}^{+}$be defined by

$$
p(x, y)=|x-y|+\max \{x, y\}, \quad \forall x, y \in X .
$$

Then, $(X, p)$ is a 0 -complete partial metric space. Note that the metric induced by $p$ is given by $d(x, y)=3|x-y|$ for all $x, y \in X$. Define $f, g: X \rightarrow X$ by

$$
\begin{array}{llll}
f 0=0, & f 1=0, & f 2=1, & f 3=1, \\
g 0=0, & g 1=0, & g 2=0, & g 3=1 .
\end{array}
$$

Now, by a careful observation one can see that $f$ and $g$ satisfy the condition (28) of Corollary 11, with $F(t)=\log t$ for all $t \in \mathbb{R}^{+}, \tau \in(0, \log (3 / 2)]$, and $f$ and $g$ have a unique common fixed point, namely, $0 \in X$ with $p(0,0)=0$. While, $f$ and $g$ do not satisfy the condition (29) of Corollary 12. Indeed, for $x=2, y=2$, there are no $F \in \mathscr{F}$ and $\tau>0$ such that $\tau+F(p(f x, g y)) \leq F(p(x, y))$. Again, $f$ and $g$ do not satisfy the metric versions of Condition (28) of Corollary 11. Indeed, $x=2, y=1$ are the points where the induced metric and usual metric versions of condition (28) of Corollary 11 are not satisfied.

\section{References}

[1] S. G. Matthews, "Partial metric topology," Annals of the New York Academy of Sciences, vol. 728, pp. 183-197, 1994.

[2] A. Amini-Harandi, "Metric-like spaces, partial metric spaces and fixed points," Fixed Point Theory and Applications, vol. 2012, article 204, 2012.

[3] A. G. Bin Ahmad, Z. M. Fadail, V. C. Rajić, and S. Radenović, "Nonlinear contractions in 0-complete partial metric spaces," Abstract and Applied Analysis, vol. 2012, Article ID 451239, 12 pages, 2012.

[4] C. Di Bari, M. Milojević, S. Radenović, and P. Vetro, "Common fixed points for self-mappings on partial metric spaces," Fixed Point Theory and Applications, vol. 2012, article 140, 2012.

[5] C. Di Bari, Z. Kadelburg, H. K. Nashine, and S. Radenović, "Common fixed points of $g$-quasicontractions and related mappings in 0-complete partial metric spaces," Fixed Point Theory and Applications, vol. 2012, article 113, 2012.

[6] D. Đukić, Z. Kadelburg, and S. Radenović, "Fixed points of Geraghty-type mappings in various generalized metric spaces," Abstract and Applied Analysis, vol. 2011, Article ID 561245, 13 pages, 2011.

[7] D. Ilić, V. Pavlović, and V. Rakočević, "Extensions of the Zamfirescu theorem to partial metric spaces," Mathematical and Computer Modelling, vol. 55, no. 3-4, pp. 801-809, 2012.

[8] D. Paesano and P. Vetro, "Suzuki's type characterizations of completeness for partial metric spaces and fixed points for partially ordered metric spaces," Topology and Its Applications, vol. 159, no. 3, pp. 911-920, 2012.

[9] F. Vetro and S. Radenović, "Nonlinear $\psi$-quasi-contractions of Ćirić-type in partial metric spaces," Applied Mathematics and Computation, vol. 219, no. 4, pp. 1594-1600, 2012.

[10] H. Aydi, "Fixed point results for weakly contractive mappings in ordered partial metric spaces," Journal of Advanced Mathematical Studies, vol. 4, no. 2, pp. 1-12, 2011.

[11] H. Aydi, "Fixed point theorems for generalized weakly contractive condition in ordered partial metric spaces," Journal of Nonlinear Analysis and Optimization, vol. 2, no. 2, pp. 269-284, 2011.

[12] H. Aydi, "Some coupled fixed point results on partial metric spaces," International Journal of Mathematics and Mathematical Sciences, vol. 2011, Article ID 647091, 11 pages, 2011.

[13] H. Aydi, "Some fixed point results in ordered partial metric spaces," Journal of Nonlinear Science and its Applications, vol. 4, no. 3, pp. 210-217, 2011.

[14] H. Aydi, M. Abbas, and C. Vetro, "Partial Hausdorff metric and Nadler's fixed point theorem on partial metric spaces," Topology and Its Applications, vol. 159, no. 14, pp. 3234-3242, 2012.

[15] H. K. Nashine, Z. Kadelburg, S. Radenović, and J. K. Kim, "Fixed point theorems under Hardy-Rogers contractive conditions on 0 -complete ordered partial metric spaces," Fixed Point Theory Applications, vol. 2012, article 180, 2012.

[16] I. Altun and A. Erduran, "Fixed point theorems for monotone mappings on partial metric spaces," Fixed Point Theory and Applications, vol. 2011, Article ID 508730, 10 pages, 2011. 
[17] I. Altun, F. Sola, and H. Simsek, "Generalized contractions on partial metric spaces," Topology and Its Applications, vol. 157, no. 18, pp. 2778-2785, 2010.

[18] L. Ćirić, B. Samet, H. Aydi, and C. Vetro, "Common fixed points of generalized contractions on partial metric spaces and an application," Applied Mathematics and Computation, vol. 218, no. 6, pp. 2398-2406, 2011.

[19] M. Bukatin, R. Kopperman, S. Matthews, and H. Pajoohesh, "Partial metric spaces," The American Mathematical Monthly, vol. 116, no. 8, pp. 708-718, 2009.

[20] N. Hussain, Z. Kadelburg, S. Radenović, and F. Al-Solamy, "Comparison functions and fixed point results in partial metric spaces," Abstract and Applied Analysis, vol. 2012, Article ID 605781, 15 pages, 2012.

[21] R. Heckmann, "Approximation of metric spaces by partial metric spaces," Applied Categorical Structures, vol. 7, no. 1-2, pp. 71-83, 1999.

[22] S. J. O'Neill, "Partial metrics, valuations, and domain theory," Annals of the New York Academy of Sciences, vol. 806, pp. 304315, 1996.

[23] S. Romaguera, "A Kirk type characterization of completeness for partial metric spaces," Fixed Point Theory and Applications, vol. 2010, Article ID 493298, 6 pages, 2010.

[24] S. Romaguera, "Fixed point theorems for generalized contractions on partial metric spaces," Topology and Its Applications, vol. 159, no. 1, pp. 194-199, 2012.

[25] S. Romaguera, "Matkowski's type theorems for generalized contractions on (ordered) partial metric spaces," Applied General Topology, vol. 12, no. 2, pp. 213-220, 2011.

[26] T. Abdeljawad, "Fixed points for generalized weakly contractive mappings in partial metric spaces," Mathematical and Computer Modelling, vol. 54, no. 11-12, pp. 2923-2927, 2011.

[27] T. Abdeljawad, E. Karapınar, and K. Taş, "Existence and uniqueness of a common fixed point on partial metric spaces," Applied Mathematics Letters, vol. 24, no. 11, pp. 1900-1904, 2011.

[28] W. Shatanawi, B. Samet, and M. Abbas, "Coupled fixed point theorems for mixed monotone mappings in ordered partial metric spaces," Mathematical and Computer Modelling, vol. 55, no. 3-4, pp. 680-687, 2012.

[29] Z. Kadelburg, H. K. Nashine, and S. Radenović, "Fixed point results under various contractive conditions in partial metric spaces," Revista de la Real Academia de Ciencias Exactas, Fisicas y Naturales A, 2012.

[30] D. Wardowski, "Fixed points of a new type of contractive mappings in complete metric spaces," Fixed Point Theory and Applications, vol. 2012, article 94, 2012.

[31] L. B. Ćirić, "Fixed points for generalized multi-valued contractions," Matematički Vesnik, vol. 9, no. 24, pp. 265-272, 1972.

[32] L. B. Ćirić, "Generalized contractions and fixed-point theorems," Publications de l'Institut Mathématique, vol. 12, no. 26, pp. 19-26, 1971.

[33] S. Oltra and O. Valero, "Banach's fixed point theorem for partial metric spaces," Rendiconti dell'Istituto di Matematica dell'Università di Trieste, vol. 36, no. 1-2, pp. 17-26, 2004.

[34] E. Karapınar, "Ćirić types nonunique fixed point theorems on partial metric spaces," Journal of Nonlinear Science and Its Applications, vol. 5, no. 2, pp. 74-83, 2012. 


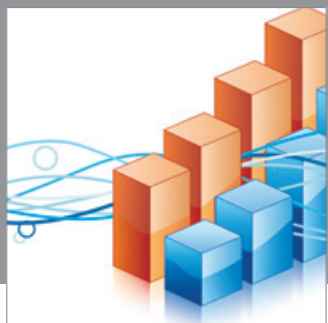

Advances in

Operations Research

mansans

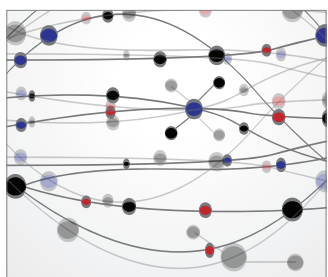

The Scientific World Journal
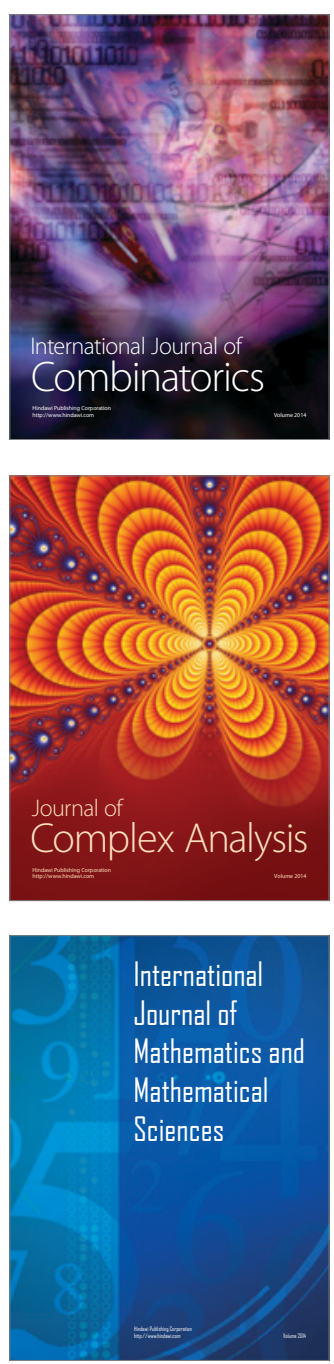
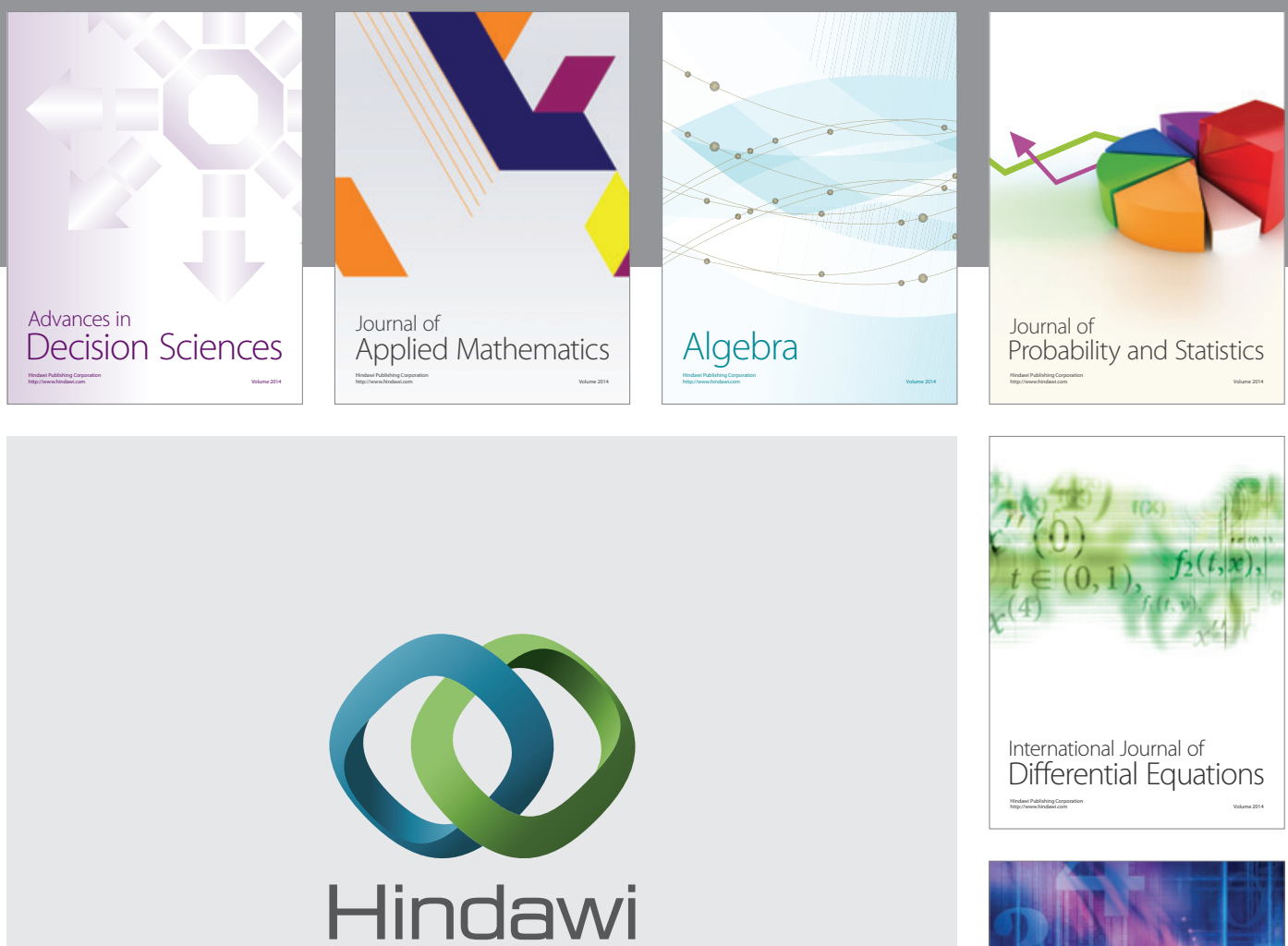

Submit your manuscripts at http://www.hindawi.com
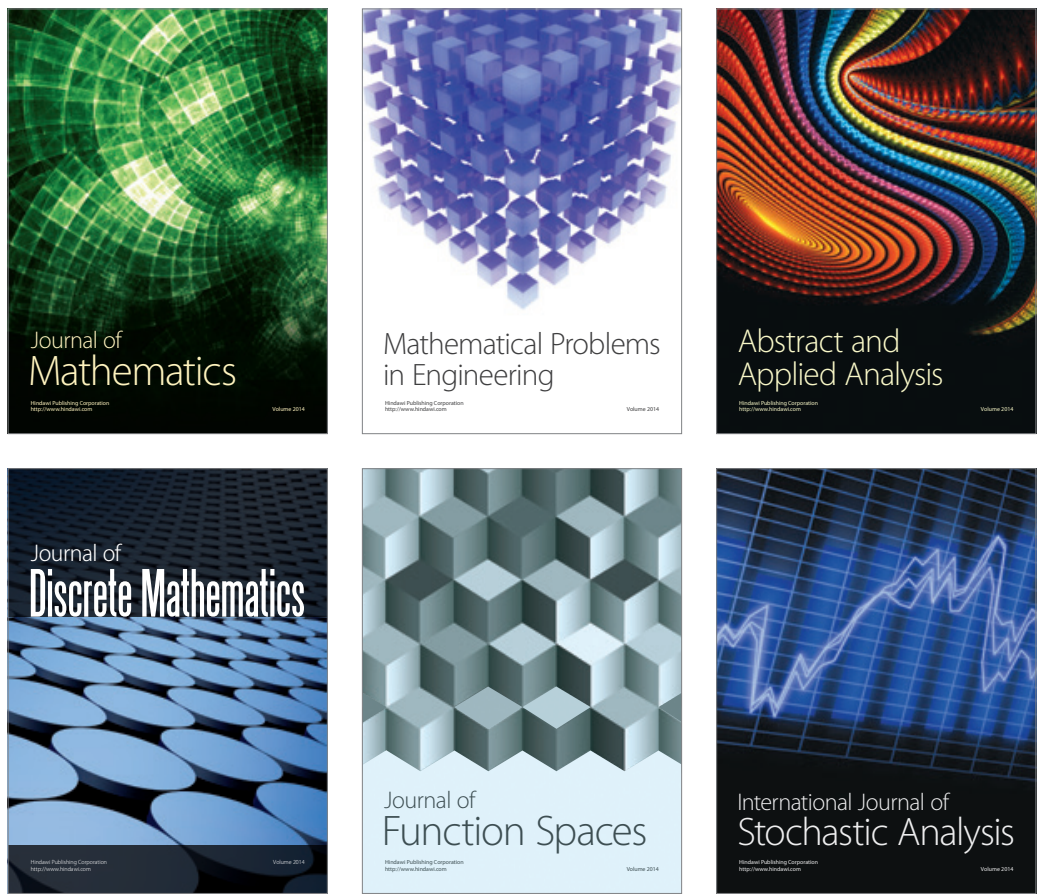

Journal of

Function Spaces

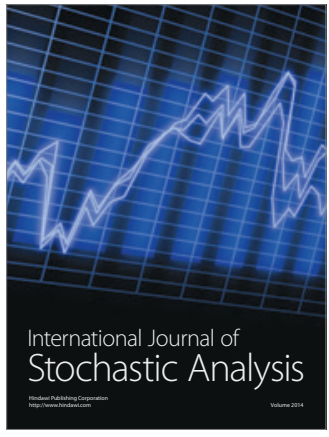

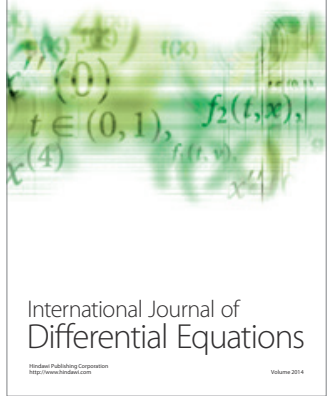
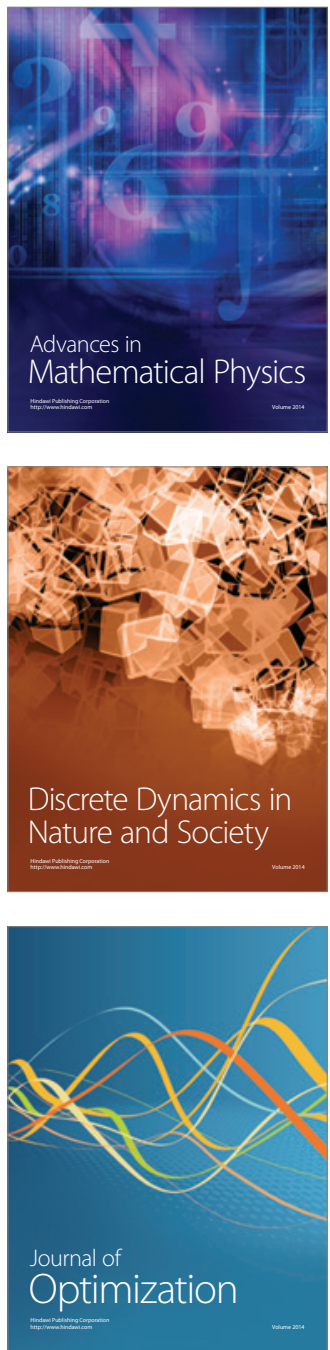